\title{
Symptomatic Improvement of Gastroparesis with Granisetron Transdermal System
}

\author{
Hye-Kyung Jung \\ Department of Internal medicine, Ewha Womans University School of Medicine, Seoul, Korea
}

Article: Granisetron transdermal system for treatment of symptoms of gastroparesis: a prescription registry study Midani D, Parkman HP

(J Neurogastroenterol Motil 2016;22:650-655)

Gastroparesis is a chronic relapsing condition that presents gastrointestinal (GI) symptoms related with delayed gastric emptying, that occurs in disorders such as diabetes mellitus, scleroderma, anorexia nervosa, Parkinson's disease, and idiopathic. ${ }^{1}$ It includes nausea, vomiting, early satiation, postprandial fullness or epigastric pain. Prokinetics including serotonin receptor (eg, 5- $\left.\mathrm{HT}_{4}\right)$ agonists that stimulate gastric motor activity and show similar efficacy with metoclopramide in reducing nausea. ${ }^{2}$

The study published in the recent issue of Journal of Neurogastroenterology and Motility was conducted in 51 patients with gastroparesis (13 diabetic, 35 idiopathic) to evaluate symptom improvement with the transdermal granisetron delivery system (GTS) in an open-label prescription registry study. ${ }^{3}$ Patients were applied with GTS for 2 weeks. Among them, 76\% (31/51) patients reported symptom improvement, especially nausea and vomiting. In terms of safety profiles, 12 patients reported skin problems, such as redness at the site of the patch and itching; one patient reported palpitation. However, there were no cardiovascular adverse events.

The drug delivery in patients with gastroparesis is frequently inconsistent because of poor oral intake and delayed gastric empty- ing. Therefore, oral treatment with a variety of prokinetic agents can be ineffective and parenteral administration of prokinetics is not available. Transdermal drugs in patients with gastroparesisis are absorbed through the skin and bypass the GI tract and hepatic firstpass metabolism. ${ }^{4}$ Furthermore, it probably increases the drug compliance. The transdermal granisetron patch is effective in patients with chemotherapy-induced emesis, mainly related with modulation of perception from the GI tract. ${ }^{5}$

This study revealed that nausea, vomiting and other GI symptoms are markedly improved by GTS. Especially, the symptom of nausea improved most significantly with treatment among many of the gastroparesis symptoms. It is difficult to verify the treatment efficacy beyond the placebo effect on gastroparesis because of the lack of placebo arm in this study. In a previous study with domperidone or metoclopramide, the symptom improvement was reported in 40 $90 \%$ of gastroparesis, ${ }^{6}$ but the placebo effect was reported as $50 \%$.

In summary, the granisetron transdermal patch seems to be an alternative treatment for control of nausea and vomiting in a subset of patients with refractory gastroparesis.

Received: September 13, 2016 Revised: None Accepted: September 13, 2016

() This is an Open Access article distributed under the terms of the Creative Commons Attribution Non-Commercial License (http://creativecommons. org/licenses/by-nc/4.0) which permits unrestricted non-commercial use, distribution, and reproduction in any medium, provided the original work is properly cited.

*Correspondence: Hye-Kyung Jung, MD Department of Internal Medicine, Ewha Womans University Medical Center, 1071, Anyangcheon-ro, Yangcheon-gu, Seoul 07985, Korea

Tel: +82-2-2650-2874, Fax: +82-2-2655-2874, E-mail: junghk@ewha.ac.kr 
Financial support: None.

\section{Conflicts of interest: None.}

\section{References}

1. Jung HK, Choung RS, Locke GR III, et al. The incidence, prevalence, and outcomes of patients with gastroparesis in Olmsted County, Minnesota, from 1996 to 2006. Gastroenterology 2009;136:1225-1233.

2. Barrett TW, DiPersio DM, Jenkins CA, et al. A randomized, placebocontrolled trial of ondansetron, metoclopramide, and promethazine in adults. Am J Emerg Med. 2011;29:247-255.

3. Midani D, Parkman HP. Granisetron transdermal system for treatment of symptoms of gastroparesis: a prescription registry study. J Neurogastroenterol Motil 2016;22:650-655.

4. Guy RH, Hadgraft J. Transdermal drug delivery: a perspective. J Control Release 1987;4:237-251.

5. Hasler WL. Serotonin and the GI tract. Curr Gastroenterol Rep 2009;11:383-391.

6. Parkman HP, Carlson MR, Gonyer D. Metoclopramide nasal spray is effective in symptoms of gastroparesis in diabetics compared to conventional oral tablet. Neurogastroenterol Motil 2014;26:521-528.

7. Ejskjaer N1, Dimcevski G, Wo J, et al. Safety and efficacy of ghrelin agonist TZP-101 in relieving symptoms in patients with diabetic gastroparesis: a randomized, placebo-controlled study. Neurogastroenterol Motil 2010;22:1069-e281. 